\title{
Frequency And Shape Of Torus Palatinus In Relation To Age And Gender In Karachi
}

Daud Mirza, Saima Mazhar, Sameer Quraeshi, Usman Mahmood, Nasir Jamal Baig, Muhammad Shahrukh Khan Sadiq, Syed Ahmed Omer, Saad Uddin Siddiqui

ABSTRACT:

Objective: The aim of this study was to determine the frequency and shape of torus palatinus and to assess its gender and age-related differences in the population of Karachi, the metropolitan city of Pakistan.

Methodology: This was a cross sectional study with non-probability convenience sampling method conducted at Bahria University Medical \& Dental College (BUMDC), Karachi. The presence of tori was observed by clinical examination and palpation. The shape was also investigated by presence or absence and classified as flat, spindle and nodular shaped tori. The data was analyzed by using Statistical Package for Social Science version 23. The Chi-square test was used to test for group differences of sex and age association with the prevalence of tori. Difference between groups with $\mathrm{P}<0.05$ was considered significant.

Results: A total of 1203 patients were screened in which torus palatinus was found in 141 (11.7\%) patients. Present study findings showed torus palatinus was more prevalent in males 76 (53.9\%). It was dominant in 31-60 years of age group (47.5\%) with significant $\mathrm{P}=0.000$. Shapes of torus palatinus were compared with gender in which flat shape was more frequent in both male and female with significant P-value of 0.015 .

Conclusion: Torus Palatinus is a rare bony exostosis of the oral cavity. Even though, it is an asymptomatic anatomical variation it expresses itself in unique shapes and patterns. The prevalence varies with respect to age and gender.

Keywords: Torus Palatinus, Bony exostosis, Shapes, Pattern, Prevalence

\section{INTRODUCTION:}

Torus Palatinus (TP) is referred as a benign intraoral anatomical bony protuberance that is located along the midline of the hard palate ${ }^{1}$. It is formed by excessive functioning of osteoblasts leading to bone deposition along

Daud Mirza,
Associate Professor and Head of Department Oral Pathology,
I Bahria University Medical and Dental College.
I Saima Mazhar,
I Lecturer, Department of Periodontology,
Bahria University Medical and Dental College
I Sameer Quraeshi,
Assistant Professor, Department of Prosthodontics,
I Fatima Jinnah Dental College
I Usman Mahmood,
I Lahore Medical \& Dental College
I Nasir Jamal Baig,
I Assistant Professor, HOD Pakistan Navy Dental Centre,
INS Shifa.
I Muhammad Shahrukh Khan Sadiq,
I Becturer, Department Oral Pathology,
I Sahria University Medical and Dental College
I Assed Ahmed Omer,
I Materials,
I Saad Udofessor \& HOD, Department of Science of Dental
I RMO OMFS, Civil Hospital Karachi
I Received: 04-09-2018
I Accepted: 08-10-2018
I midline of the vault ${ }^{2}$. It is also designated as hyperostosis, exostosis and osteomas ${ }^{3}$.

The etiology of TP is not well established but researchers have attempted to clarify the influence of genetics in its formation ${ }^{4}$. Others have suggested environmental, nutritional, masticatory hyperfunction, superficial traumatic injuries and continuous growth as its predisposing factors ${ }^{5}$. However, more widely accepted theory suggests genetics and environmental factors to have a strong association with $\mathrm{TP}^{6}$. The development begins in early adult life progressing and enlarging slowly over time ${ }^{7}$. Its presentation before the age of 10 years is very rare usually developing in second to third decade of life ${ }^{8}$. In most instances TP are asymptomatic however, extremely large sizes may need to be surgically removed since they may interfere with denture construction $^{9,10}$. The aim of present study was to determine the frequency and shape of TP and to assess its sex and agerelated differences in the population of Karachi, the metropolitan city of Pakistan.

\section{MATERIALS AND METHODS:}

This was a cross-sectional study with non-probability convenience sampling. Study was conducted in dental out patients department of Bahria University Medical \& Dental College (BUMDC), Karachi from June, 2017 to June, 2018. The present study comprised of 1203 edentulous subjects (561 men and 642 women) aged between 10 to 90 years. The Ethical approval was obtained from the College ethical committee, BUMDC. Informed consent was taken from all the participants included in the study. Subjects were assorted 
based on their sex and were classified into three age groups, namely 10-30, 31-60 and 61-90 years. The existence of tori was determined by clinical examination and palpation, and result of the test was recorded as present or absent. Patients who refused to participate in this study were excluded. Changes in the mid part of the palate were analyzed and were classified as flat, spindle and nodular shaped tori. In case of presence of tori, study casts were made using Kromopan Alginate (alginate impression material) for assessment of the size, shape, and location of the tori. The data was analyzed by using Statistical Package for Social Science (SPSS) for Windows Inc. Version 23.0 Chicago, Illinois. The Chi-square test was used to test for group differences and sex and age association with the presence or absence and shape of TP. The difference between groups with $P=0.05$ was considered significant.

\section{RESULTS:}

Total 1203 dental patients participated in this study. Out of which 561 (46.63\%) were males and 642 females (53.37\%). The mean age of patients was 31.94 and $\mathrm{STD} \pm 15.97$. TP was observed in $141(11.7 \%)$ patients. Present study findings showed TP was more prevalent in males 76 (53.9\%) than female $65(46.1 \%)$ as shown in (Figure 1). This bony exostosis was also investigated according to age groups and found significant in present study $\mathrm{P}<0.05$. TP was dominant in 31-60 years of age group recording 67 cases $(47.5 \%)$ and

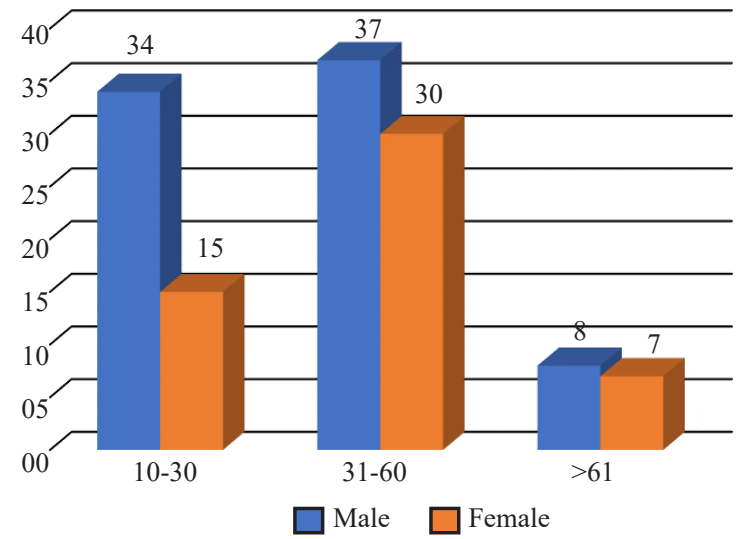

Figure 1: Age and gender distribution of patients with TP

\begin{tabular}{|c|c|c|l|}
\hline \multirow{2}{*}{$\begin{array}{c}\text { Age } \\
\text { (years) }\end{array}$} & \multicolumn{2}{|c|}{ TP } & \multirow{2}{*}{ P-value } \\
\cline { 2 - 3 } & Present & Absent & \\
\hline $10-30$ & $59,41.8 \%$ & $673,63.4 \%$ & \\
\hline $31-60$ & $67,47.5 \%$ & $318,29.9 \%$ & \multirow{2}{*}{$0.000 *$} \\
\hline в 61 & $15,10.6 \%$ & $71,6.7 \%$ & \\
\hline Total & $141,100.0 \%$ & $1062,100.0 \%$ & \\
\hline
\end{tabular}

*Chi square test was applied

$* \mathrm{P}=0.05$ considered to be statistically significant

Table 1: Distribution of TP according to age groups

\begin{tabular}{|l|c|c|c|c|}
\hline \multirow{2}{*}{ Gender } & \multicolumn{3}{|c|}{ Shape } & \multirow{2}{*}{ P-value } \\
\cline { 2 - 4 } & Spindle & \multicolumn{1}{|c|}{ Flat } & \multicolumn{1}{|c|}{ Nodular } & \\
\hline Male & $16,47.1 \%$ & $49,52.7 \%$ & $10,71.4 \%$ & \\
\hline Female & $18,52.9 \%$ & $44,47.3 \%$ & $4,28.6 \%$ & \multirow{2}{*}{$0.015^{*}$} \\
\hline Total & $34,100.0 \%$ & $93,100.0 \%$ & $14,100.0 \%$ & \\
\hline
\end{tabular}

*Chi square test was applied

$* \mathrm{P}=0.05$ considered to be statistically significant

Table 2: Distribution of Shape/pattern of TP according to gender

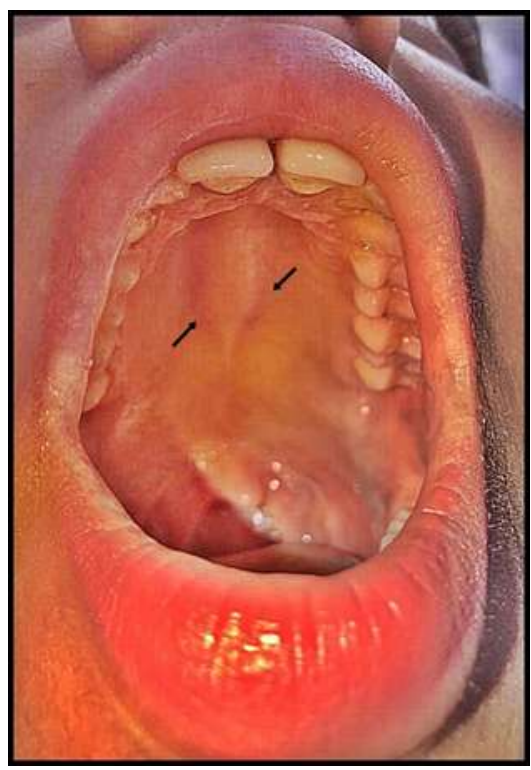

Figure 2: Spindle-shaped Torus Palatinus

least one was in 61-90 years of age group as shown in (Table 1).

Cross tabulation of presence of TP with shape was further evaluated. Flat shaped torus palatinus was present in majority of cases in both gender followed by spindle-shaped and nodular-shaped (Table 2).

\section{DISCUSSION:}

TP is an exostosis of hard plate and is usually considered as an anatomical variation instead of a pathological entity. Studies shows the TP prevalence ranges from 1.4 to $66.0 \%$ in different populations. ${ }^{11}$ Notable contrast in prevalence of TP was observed in different races. The Mongoloids (East Asians) are reported in superior numbers than Caucasians (Europeans). While TP were reported to be less common in Africans than Caucasians ${ }^{15}$. In the present study, our findings showed TP was highly present in males than females. The study conducted in Croatia showed male prevelance. ${ }^{2}$ While ample number of studies showed contrasting results where the prevalence of TP was higher in females than in males. According to one Saudi Arabian study, female and male prevalence was reported to be $22.2 \%$ and $10.0 \%$ respectively ${ }^{11}$. Similarly, in another study conducted in 
Turkey, female predilection was observed as reported cases accounting to more than $5 \% .{ }^{12}$. In Thai population, the majority of TP patients were females comprising $70.5 \%$ of the sample of TP patients ${ }^{13}$. Research has shown that the palatine tori were reported in females, and this was referred to a dominant type $\mathrm{x}$ chromosome ${ }^{14}$.

There is an age-related disparity of TP as reported in various literature. Previous studies revealed higher TP prevalence was during the second to third decades of life which is consistent with our results ${ }^{15}$. Apinhasmit et al reported similar results in Thailand with second and third decades having the most patients of $\mathrm{TP}^{13}$. In Malay population, second decade was revealed to be most likely associated with TP according to a research by Hiremath et $\mathrm{al}^{16}$. On the other hand, several studies reported tori in fifth decade of life ${ }^{2}$.

The palatal tori are classified according to their shape as flat, spindle, nodular and lobular shaped. Flat shaped tori was found to be higher in frequency and nodular type was rarest found in both genders in our study ${ }^{17}$. In accordance with our study, flat shaped TP had the highest prevalence in the Iraqi population (7.7\%) according to a study by Faiza M. Abdul-Ameer. Spindle shaped tori came later with an occurrence of $6.8 \%$ in the populace. Nodular TP has the least reported cases with less than $1 \%{ }^{18}$. Similar results were reported by a study conducted by Yildiray Sisman et al in Turkey. $62.7 \%$ of total TP patients were diagnosed with flat shaped while $36.3 \%$ had spindle shaped occurrence ${ }^{12}$. This variation may be due to difference in number of arch forms samples reported for both genders as the ovoid arch form reported in higher percentage than others $(68 \%)^{19}$. Differences occur due to type of irritation expose to palate, amount of occlusal forces exerted by each genders, different in age groups, diet variation, hormonal change, number of missing teeth, absent or present of restoration with complete or partial removable restorations ${ }^{20,21}$.

Tori are usually an asymptomatic clinical finding with no treatment normally necessary ${ }^{22,23}$. TP often needs surgery to reduce the amount of bone present, as it causes chronic trauma, interfering with oral function or fabrication and replacement of denture base or framework ${ }^{24,25}$. The inconsistent results of various authors possibly are due to the differences in number of subjects and different geographic location $^{26,27}$. A unique study carried by Mirza et al in Pakistan showed the association of TP among various ethnicities. Urdu speaking community has the highest recorded TP cases in Pakistan ${ }^{28}$.

Treatment for TP is not often recommended unless it compromises the patient's quality of life. Surgery is the most common treatment if the tori becomes so large that it impedes the function or denture placement or has recurring traumatic surface ulceration.

\section{CONCLUSION:}

Torus Palatinus is one peculiar bony exostosis of the mouth that varies in individuals on the basis of multiple factors. The current study finding showed male dominance with flat-shaped torus palatinus. Even though, it is traditionally asymptomatic the authors are of the view that comprehensive study on a large population sample is a need of time to decipher and understand the link of torus palatinus with its causative factors.

\section{ACKNOWLEDGEMENT:}

The authors are thankful to all Heads of Dental department $\&$ Faculty members who co-operated us for the patients screening of this study.

\section{REFERENCES:}

1. Jainkittivong A, Apinhasmit W, Swasdison S. Prevalence and clinical characteristics of oral tori in 1,520 Chulalongkorn University Dental School patients. Surg Radiol Anat 2007;29:125-31.

2. Simunkoviæ SK, Boziæ M, Alajbeg IZ, Dulciæ N, Boras VV. Prevalence of torus palatinus and torus mandibularis in the Split-Dalmatian County, Croatia. Coll Antropol. 2011.

3. Al Sebaie D, Alwirikat M. Prevalence of torus palatinus and torus mandibularis in Jordanian population. Pak Oral Dent J2011.

4. Yoshinaka M, Ikebe K, Furuya-Yoshinaka M, Hazeyama T, Maeda Y.Prevalence of torus palatinus among a group of Japanese elderly. J Oral Rehabil 2010;37:848-53.

5. Morphological and clinical characteristics of the torus palatinus and torus mandibularis in a sample of young and adults' Romanian people Scrieciu M, et al. 2016)

6. García-García AS, Martínez-González JM, Gómez-Font R, Soto-Rivadeneira A, Oviedo-Roldán L. Current status of the toruspalatinus and torus mandibularis. Med Oral Patol Oral CirBucal. 2010.

7. Al Quran FA, Al-Dwairi ZN.Torus palatinus and torus mandibularis in edentulous patients. J Contemp Dent Pract 2006.

8. JO Agbaje, MO Arowojolu, B Kolude, JO Lawoyin. Torus Palatinus and Torus Mandibularis in a Nigerian Population. African J Oral Health 2005.

9. Torus Palatinus: A New Anatomical Correlation with Bone Density in Postmenopausal Women. The Journal of Clinical Endocrinology \& Metabolism, 2003;88(5):2081-2086.

10. Abrams S. Complete denture covering mandibular tori using three base materials: a case report. J Can Dent Assoc. 2000.

11. AlZarea BK. Prevalence and pattern of torus palatinus and torus mandibularis among edentulous patients of Saudi Arabia. Clinical Interventions in Aging. 2016;11:209-213.

12. Yildiz E, Deniz M, Ceyhan O. Prevalence of torus palatinus in Turkish Schoolchildren. Surg Radiol Anat. 2005;27:368-371.

13. Apinhasmit W, Jainkittivong A, Swasdison S. Torus palatinus and torus mandibularis in a Thai population. Sci Asia 2002;28:105-111.

14. García-García AS, Martínez-González JM, Gómez-Font R, Soto-Rivadeneira A, Oviedo-Roldán L Med Oral Patol Oral Cir Bucal. 2010; 15(2):e353-60).

15. Kerdpo D, Sirirungrojying S. A clinical study of oral tori in Southern Thailand: prevalence and the relation to parafunctional activity. Eur J Oral Sci. 1999;107:9-13. 
16. Hiremath VK, Husein A, Mishra N. Prevalence of torus palatinus and torus mandibularis among Malay population. Journal of International Society of Preventive \& Community Dentistry. 2011;1(2):60-64.

17. Sonnier KE, Horning GM, Cohen ME. Palatal tubercles, palatal tori, and mandibular tori: prevalence and anatomical features in a U.S. population. J Periodontol. 1999;70:329-336.

18. Sisman Y, Ertas ET, Gokce C, Akgunlu F. Prevalence of torus palatinus in cappadocia region population of Turkey. Eur J Dent. 2008;2: 269-275.

19. Abdul-Ameer, Faiza M.. "Correlation of Prevalence of Torus Palatinus and Torus Mandibularis with the Form of Maxillary and Mandibular Arches in Iraqi Population.”; 2016.

20. Correlation of Prevalence of Torus Palatinus and Torus Mandibularis with the Form of Maxillary and Mandibular Arches in Iraqi Population. June 2016.

21. Sawair FA, Shayyab MH, Al-Rababah MA, Saku T. Prevalence and clinical characteristics of tori and jaw exostoses in a teaching hospital in Jordan. Saudi Med J. 2009;30:1557-62.
22. Patil S, Maheshwari S, Khandelwal SK. Prevalence of torus palatinus and torus mandibularis in an Indian population. Saudi J Oral Sci. 2014;1:94-97.

23. Al-Bayaty HF, Murti PR, Matthews R, Gupta PC. An epidemiological study of tori among 667 dental outpatients in Trinidad and Tobago, West Indies. Int Dent J. 2001;51:300-304.

24. Bruce I, Ndanu TA, Addo ME. Epidemiological aspects of oral tori in a Ghanaian community. Int Dent J. 2004;54:78-82.

25. Chohayeb AA, Volpe AR. Occurrence of torus palatinus and mandibularis among women of different ethnic groups. Am J Dent. 2001;14:278-280.

26. Correlation of Prevalence of Torus Palatinus and Torus Mandibularis with the Form of Maxillary and Mandibular Arches in Iraqi Population. June 2016.

27. Vaduganathan M, Marciscano AE, Olson KR. Torus palatinus. Proceedings (Baylor University Medical Center). 2014;27(3):259.

28. Mirza D, Hakeem S, Omer SA, Rizvi KF. Frequency of Torus Palatinus; A Study done in a teaching hospital in Karachi. Pakistan Oral \& Dental Journal, 2013; 33(1):58-62. 